\title{
Enhanced CO Oxidation on Oxide/Metal Interface: From Ultra-High Vacuum to Near-Atmospheric Pressures.
}

Qiushi Pan, ${ }^{1}$ Xuefei Weng, ${ }^{1,2}$ Mingshu Chen, ${ }^{2}$ Livia Giordano, ${ }^{3}$ Gianfranco Pacchioni, ${ }^{3}$ Claudine Noguera, ${ }^{4,5}$ Jacek Goniakowski, ${ }^{4,5 *}$ Shamil Shaikhutdinov, ${ }^{1 *}$ Hans-Joachim Freund $^{1}$

\footnotetext{
${ }^{1}$ Abteilung Chemische Physik, Fritz-Haber-Institut der Max-Planck-Gesellschaft, Faradayweg 4-6, 14195 Berlin, Germany

${ }^{2}$ State Key Laboratory of Physical Chemistry of Solid Surfaces, South Siming Road 422, Xiamen, Fujian 361005, China

${ }^{3}$ Dipartimento di Scienza dei Materiali, Universitá di Milano-Bicocca, via Cozzi, 55 - 20125 Milano, Italy

${ }^{4}$ CNRS, UMR 7588, Institut des Nanosciences de Paris, F-75005 Paris, France

${ }^{5}$ Sorbonne Universités, UPMC Univ. Paris 06, UMR 7588, INSP, F-75005 Paris, France
}

\begin{abstract}
We studied $\mathrm{CO}$ oxidation on $\mathrm{FeO}(111)$ films on $\mathrm{Pt}(111)$ at sub-monolayer oxide coverages at ultra-high vacuum (UHV) and near-atmospheric pressure conditions. The FeO(111) bilayer islands are inert towards $\mathrm{CO} 2$ formation. In contrast, the FeO2-x trilayer structure shows substantial $\mathrm{CO} 2$ production that reaches a maximum at( $\sim 0 \%)$ coverage at both, UHV and realistic, pressure conditions. The results provide compelling evidence that the FeO2-x/Pt(111) interface is the most active in $\mathrm{CO}$ oxidation. Although FeO2-x boundaries possesses weakly bound oxygen species, strong binding of $\mathrm{CO}$ to Pt favors the reaction at the FeO2-x/Pt interface as compared to the $\mathrm{FeO} 2-\mathrm{x} / \mathrm{FeO}$ one, thus giving a rationale to the reactivity enhancement observed in systems exposing metal/oxide boundaries. In addition, oxygen diffusion from the interior of an FeO2-x island to the active edge sites may be effective for the oxygen replenishment in the $\mathrm{CO}$ oxidation catalytic cycle.
\end{abstract}

Keywords: metal oxides; metal/oxide interface; inverse catalysts; CO oxidation; thin films.

*Corresponding authors: shaikhutdinov@fhi-berlin.mpg.de (S. Shaikhutdinov); Jacek.Goniakowski@insp.jussieu.fr (J. Goniakowski) 


\section{INTRODUCTION}

The catalytic oxidation of $\mathrm{CO}$ on metals is one of the most widely studied reactions in heterogeneous catalysis. To unravel the reaction mechanisms within the "surface science" approach, enormous number of studies has been carried out on model systems, primarily employing metal single crystal surfaces under ultra-high vacuum (UHV) conditions. Recently, it has been recognized that ultrathin oxide films of transition metals grown on a metal support or those, natively formed on the noble metal surfaces under realistic pressure conditions, may show high activity, in particular at low temperatures, where "conventional" metal catalysts are, in essence, inert. ${ }^{[1]}$ In attempts to find key factors which govern the reaction on such oxide films, a comparative study of $\mathrm{CO}$ oxidation over Fe, Mn, Zn, and Ru oxide ultra-thin films at near-atmospheric pressures has been performed in our laboratories. ${ }^{[2]}$ The results showed that oxygen binding energy in the oxide films, as measured by temperature programmed desorption (TPD), plays the decisive role for the reaction: The more weakly bound surface oxygen species, the higher the reaction rate. Therefore, the oxygen binding energy may serve as a good descriptor for oxidation reactions over thin films. It turned out, however, that the CO oxidation rate on $\mathrm{ZnO}$ monolayer films on $\mathrm{Pt}(111)$, which showed the least activity among the closed films, increases considerably at sub-monolayer (sub-ML) oxide coverage. ${ }^{[3]}$ On the other hand, such a rate enhancement was not observed for the $\mathrm{ZnO}$ films supported on $\mathrm{Ag}(111){ }^{[4]}$ The difference has been assigned to a much stronger $\mathrm{CO}$ adsorption on $\mathrm{Pt}(111)$ as compared to $\mathrm{Ag}(111)$ that increases the residence time for adsorbed $\mathrm{CO}$ and hence the probability to react with an oxygen supplied by ZnO.

Reactivity of ultrathin transition metal oxide (TMO) films is closely related to so called "strong metal-support interaction" (SMSI), ${ }^{[5]}$ which is mostly discussed in terms of a full or partial encapsulation of metal particles by a thin oxide layer stemming from a support. In particular, our own studies ${ }^{[6]}$ of Pt nanoparticles deposited onto well-defined iron oxide surfaces showed the SMSI effect via encapsulation of the Pt surface by an iron oxide layer

identified as $\mathrm{FeO}(111)$ monolayer film that readily grows on $\mathrm{Pt}(111)$ single crystal. ${ }^{[7]}$ However, the $\mathrm{FeO}(111)$ film, initially stacked as an O-Fe bilayer, transforms at elevated oxygen pressures 
to an O-rich, $\mathrm{FeO}_{2-x}$ film with a trilayer (O-Fe-O) structural motif. ${ }^{[8]}$ Although the film stoichiometry implies Fe cations in the formal oxidation state 4+, i.e. unusual for iron compounds, density functional theory (DFT) results showed that Fe ions in the trilayer structure are in the oxidation state $3+$ due to a substantial electron transfer from the Pt(111) substrate. However, for brevity, we will use $\mathrm{FeO}$ and $\mathrm{FeO}_{2}$ for the bi-layer and tri-layer structures, respectively.

The reaction mechanism of CO oxidation, addressed by DFT using the model of a continuous $\mathrm{FeO}_{2}$ film, suggested $\mathrm{CO}$ reacting with the weakly bound, topmost oxygen atom in the O-Fe-O trilayer, thus forming $\mathrm{CO}_{2}$ that desorbs leaving an oxygen vacancy behind. ${ }^{\left[{ }^{[a]}\right.}$ The vacancy must be replenished by the reaction with molecular oxygen to end the catalytic cycle.

Recently, Bao and coworkers have addressed the reactivity of $\mathrm{FeO}(111)$ and other $\mathrm{TMO}(111)$ monolayer structures on $\mathrm{Pt}(111)^{[9]}$ exposing the oxide/metal boundary. On the basis of DFT calculations, ${ }^{[9 b}$, 9c] a Pt-cation ensemble was proposed, where coordinatively unsaturated TMO cations at the edges of TMO islands are highly active for $\mathrm{O}_{2}$ adsorption and dissociation. Dissociated oxygen binds to Pt at the TMO/Pt interface and is responsible for the facile CO oxidation. The calculations employed a simplified model, using a TMO ribbon, which does not account for the experimentally observed epitaxial relationships of oxide and Pt and related lattice mismatches. Indeed, a very recent high resolution scanning tunneling microscopy (STM) study ${ }^{[10]}$ revealed several (up to five) types of edge structures of $\mathrm{FeO}(111)$ islands. To repeat, the oxide phase was modelled by the bilayer, i.e. O-TM-Pt(111), structure, which is not the structure relevant for technological CO oxidation reaction conditions, neither for FeO(111) nor for $\mathrm{ZnO}(0001)$ films on $\mathrm{Pt}(111) .{ }^{[3,8 a]}$ Following these studies, the highest reactivity on $\mathrm{FeO}(111) / \mathrm{Pt}(111)$ must be obtained on the $\mathrm{FeO}_{1-\mathrm{x}}$ islands, which are oxygen deficient at the rim and expose the unsaturated Fe cations. As a proof in this ${ }^{[9 c]}$ and following-up publications, ${ }^{[9 a, 11]}$ the authors provided a linear relationship obtained between the $\mathrm{CO}$ oxidation activity and the perimeter length only measured on the $0.25 \mathrm{ML} \mathrm{FeO(111)/Pt(111)} \mathrm{sample} \mathrm{that} \mathrm{underwent}$ gradual oxide sintering upon stepwise annealing. The reaction rate was measured by monitoring the CO/Pt related signal in ultraviolet photoelectron spectra upon dosing of $5 \times 10^{-8}$ mbar $\mathrm{O}_{2}$ to the $\mathrm{CO}$ presaturated surface at room temperature. Although Bao's group confirmed 
the formation of $\mathrm{FeO}_{2}$ trilayer islands upon oxidation of the "as grown" films at sub-monolayer coverages, they claim that these O-rich islands are inert. ${ }^{[11]}$ The latter statement is at variance with our results, which clearly showed enhanced reactivity of the closed $\mathrm{FeO}_{2}$ films. The discrepancy could, in principle, be linked to the differences in oxide preparation. ${ }^{[12]}$ Indeed, Bao and coworkers found that UHV annealing at $573 \mathrm{~K}$ is sufficient to reduce $\mathrm{FeO}_{2}$ back to $\mathrm{FeO},{ }^{[11]}$ whereas the reduction only occurs at temperatures as high as $850 \mathrm{~K}$ in our films. ${ }^{[8 a]}$ On the other hand, the apparent controversy may be related to the reaction conditions and methods of the reactivity was measured. While we monitor $\mathrm{CO}_{2}$ production at near atmospheric pressures using a conventional batch reactor and gas chromatography, Bao's group used consumption of $\mathrm{CO}$ pre-adsorbed on $\mathrm{Pt}(111)$ by the molecular oxygen beam.

Recently, Huang and coworkers ${ }^{[13]}$ have also studied the reactivity of $\mathrm{FeO}(111) / \mathrm{Pt}(111)$ surfaces in the water gas shift reaction and preferential oxidation of $\mathrm{CO}$ in excess of $\mathrm{H}_{2}$ using primarily temperature programmed desorption (TPD) technique. It appears that the oxide structure is strongly affected via the reaction with water and hydrogen. A very recent DFT study, ${ }^{[14]}$ performed on a more realistic model of $\mathrm{FeO}_{\mathrm{x}} / \mathrm{Pt}(111)$, showed that, beyond terraces of the oxygen-rich $\mathrm{FeO}_{2-x}$ phase, considered for a close film, ${ }^{[8 \mathrm{a}]}$ also $\mathrm{FeO}_{2} / \mathrm{FeO}$ and $\mathrm{FeO}_{2} / \mathrm{Pt}$ boundaries may be involved in reactions. Finally, the metal-oxide synergy effect may also result from oxygen spillover from the oxide to the metal support.

In this work, we studied reactivity of $\mathrm{FeO}(111) / \mathrm{Pt}(111)$ films at sub-monolayer coverage both in near atmospheric and UHV-compatible pressures in order to bridge the "pressure gap" that may cause some controversy in results obtained by different groups. Here we show that a much higher reactivity is, indeed, achieved by exposing an interface between the Pt support and the oxygen-rich $\mathrm{FeO}_{2-x}$ phase. Two synergetic effects concur: a low oxygen extraction energy at the $\mathrm{FeO}_{2} / \mathrm{Pt}$ interface and a strong adsorption of $\mathrm{CO}$ on $\mathrm{Pt}(111)$ in its direct vicinity. Weak adsorption of CO on oxide surfaces levels out the (negligible) role of CO adsorption characteristics in the reaction over the closed oxide films, thus rendering the oxygen binding energy as the decisive parameter for reactivity of ultrathin oxide films. ${ }^{[2]}$

\section{RESULTS AND DISCUSSION}




\section{Experimental Results}

Figure 1a shows kinetic curves obtained for $\mathrm{CO}$ oxidation over $\mathrm{FeO}(111) / \mathrm{Pt}(111)$ films at $450 \mathrm{~K}$ in the reaction mixture of $10 \mathrm{mbar} \mathrm{CO}$ and $50 \mathrm{mbar}_{2}$ (balanced by He to 1 bar) for different oxide coverages. The integral amounts of $\mathrm{CO}_{2}$ produced in reaction almost linearly grow in time indicating that the model catalysts do not suffer much from deactivation. CO titration of the open Pt sites in the spent catalysts by TPD showed essentially the same film coverage as in the "as prepared" samples (not shown here). However, the corresponding oxygen desorption signal showed a strong peak at $\sim 820 \mathrm{~K}$ (see details below), which is characteristic for the tri-layer structure. ${ }^{[8]}$ These two findings suggest that in the course of reaction the initially grown $\mathrm{FeO}(111)$ islands transform into the $\mathrm{FeO}_{2-x}$ islands, which do not dewet under the O-rich reaction conditions, in agreement with STM results of Fu et al. ${ }^{[11]}$

The reaction rate vs film coverage plot (Fig. 1b) clearly shows rate enhancement at sub$\mathrm{ML}$ coverages reaching a maximum at $\sim 0.4 \mathrm{ML}$. (We measured the rate at zero conversion to neglect any deactivation effects). The rate is substantially (by a factor of 3.5) higher than obtained for a closed, monolayer film, which is, in turn, more active than the pristine $\mathrm{Pt}(111)$ surface, in full agreement with our previous studies. ${ }^{[15]}$ Obviously, the oxide/metal interface provides reaction sites more active than those on the (interior) surface of $\mathrm{FeO}_{2}$ islands.
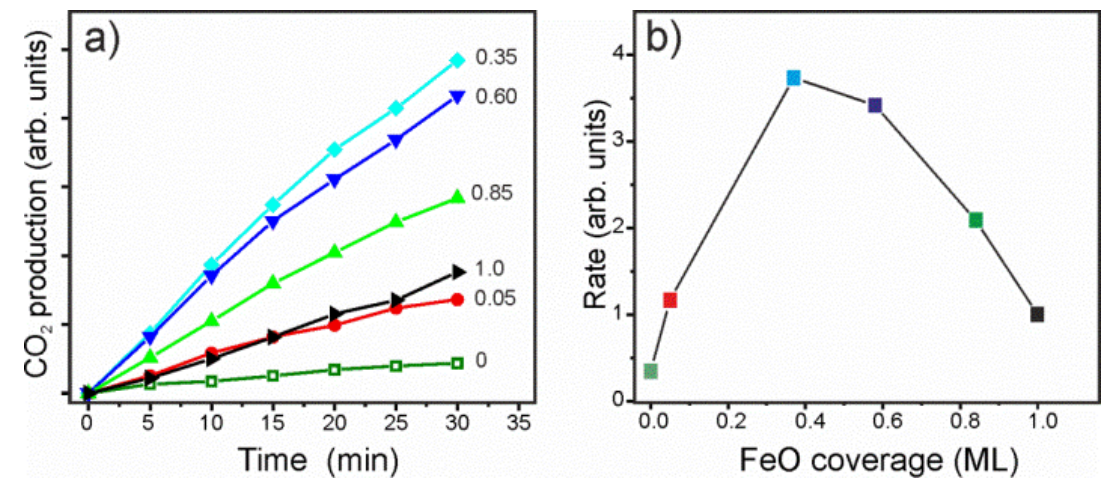

Figure 1. (a) Kinetics of $\mathrm{CO}_{2}$ production by $\mathrm{CO}$ oxidation over $\mathrm{FeO}(111)$ films grown on $\mathrm{Pt}(111)$ at the coverage as indicated. (b) Reaction rate as a function of the FeO coverage. Reaction conditions: 10 mbar $\mathrm{CO}$ and 50 mbar $\mathrm{O}_{2}$, balanced by He to 1 bar; $450 \mathrm{~K}$. 
Since oxygen binding energy was proposed as a good descriptor for reactivity of the closed ultrathin oxide films, ${ }^{[2]}$ we first analyzed the observed rate enhancement in terms of weakly bonded oxygen which may be present at the rim of oxide islands. As previously, we used $\mathrm{O}_{2}$ desorption temperature in TPD spectra as a measure of the oxygen binding strength. Figure 2 displays desorption traces of $\mathrm{O}_{2}(32 \mathrm{amu})$ measured on the partially covered $\mathrm{FeO}(111) / \mathrm{Pt}(111)$ films (in this case, $\sim 0.6 \mathrm{ML}$ ) exposed to $20 \mathrm{mbar}$ of $\mathrm{O}_{2}$ at $450 \mathrm{~K}$. The results for bare $\mathrm{Pt}(111)$ and a closed (i.e., $1 \mathrm{ML}$ ) film are shown, for comparison. Apparently, the sub-ML film exhibits desorption features of both, the $\mathrm{Pt}(111)$ support and the $\mathrm{FeO}_{2}$ trilayer, although the spectrum cannot be presented as a superposition of individual signals from the two surfaces. A sharp signal at $\sim 800 \mathrm{~K}$ can straightforwardly be assigned to desorption from the $\mathrm{FeO}_{2}$ phase, although the peak is at considerably lower temperature than observed for the closed film ( $~ 850 \mathrm{~K}$ ). Whether oxygen at the $\mathrm{FeO} / \mathrm{Pt}$ interface exhibits different from bulk desorption characteristics is difficult to judge here due to its overlapping with oxygen desorption from uncovered $\mathrm{Pt}(111)$.

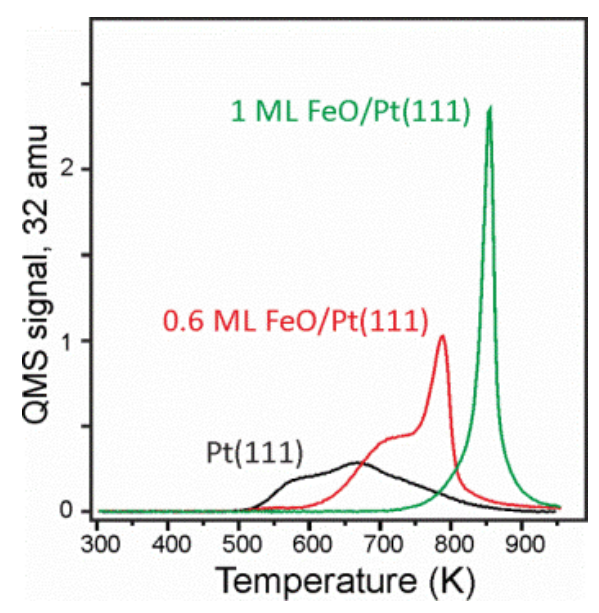

Figure 2. TPD spectra showing $\mathrm{O}_{2}(32 \mathrm{amu}$ ) desorption signal upon heating the surfaces, as indicated, exposed to $20 \mathrm{mbar}$ of $\mathrm{O}_{2}$ at $450 \mathrm{~K}$. Heating rate $3 \mathrm{~K} / \mathrm{s}$.

Nonetheless, solely on the basis of these $\mathrm{O}_{2}$ TPD spectra one could suggest that the sub$\mathrm{ML}$ oxide films are more active just because they provide more weakly bound oxygen species manifested itself by $\mathrm{O}_{2}$ desorption at lower temperature than the closed film. On the other 
hand, following the same line of arguments, one should expect to see bare $\mathrm{Pt}(111)$ even more active since the oxygen desorbs from $\mathrm{Pt}(111)$ at lower temperatures. That is definitely not the case under the reaction conditions applied here (Fig. 1). Basically, low activity of $\mathrm{Pt}(111)$ stems from the fact that strongly bonded $\mathrm{CO}$ blocks $\mathrm{O}_{2}$ dissociation in the course of LangmuirHinshelwood mechanism. On the oxide surfaces, $\mathrm{CO}$ is thought to bind only weakly, thus leveling the role of $\mathrm{CO}$ in the reaction and making the oxygen bonding as a decisive parameter for reactivity of the closed oxide films.

In order to shed more light on the reaction mechanism for $\mathrm{FeO}(111) / \mathrm{Pt}(111)$ films at sub-ML coverages, we carried out $\mathrm{CO}$ adsorption studies as a function of $\mathrm{FeO}$ coverage, exposure, and preparation conditions. The experiments were performed as follows. The $\mathrm{FeO}(111) / \mathrm{Pt}(111)$ sample was exposed to $20 \mathrm{mbar}_{2}$ at $450 \mathrm{~K}$ in the reactor and cooled to $300 \mathrm{~K}$ before oxygen was pumped out to a pressure as low as $10^{-6} \mathrm{mbar}$. Then the sample was evacuated into UHV chamber and immediately cooled down to $\sim 220 \mathrm{~K}$ prior to CO was adsorbed (typical exposure $1 \mathrm{~L}, 1$ Langmuir $=1 \times 10^{-6}$ Torr s), and TPD spectra were recorded by heating to $550 \mathrm{~K}$. After the first TPD run, the sample was again cooled down and exposed to $1 \mathrm{~L}$ $\mathrm{CO}$ at $220 \mathrm{~K}$, and the second TPD spectrum was measured. These adsorption/desorption cycles were repeated several times to monitor $\mathrm{CO}_{2}$ production. 

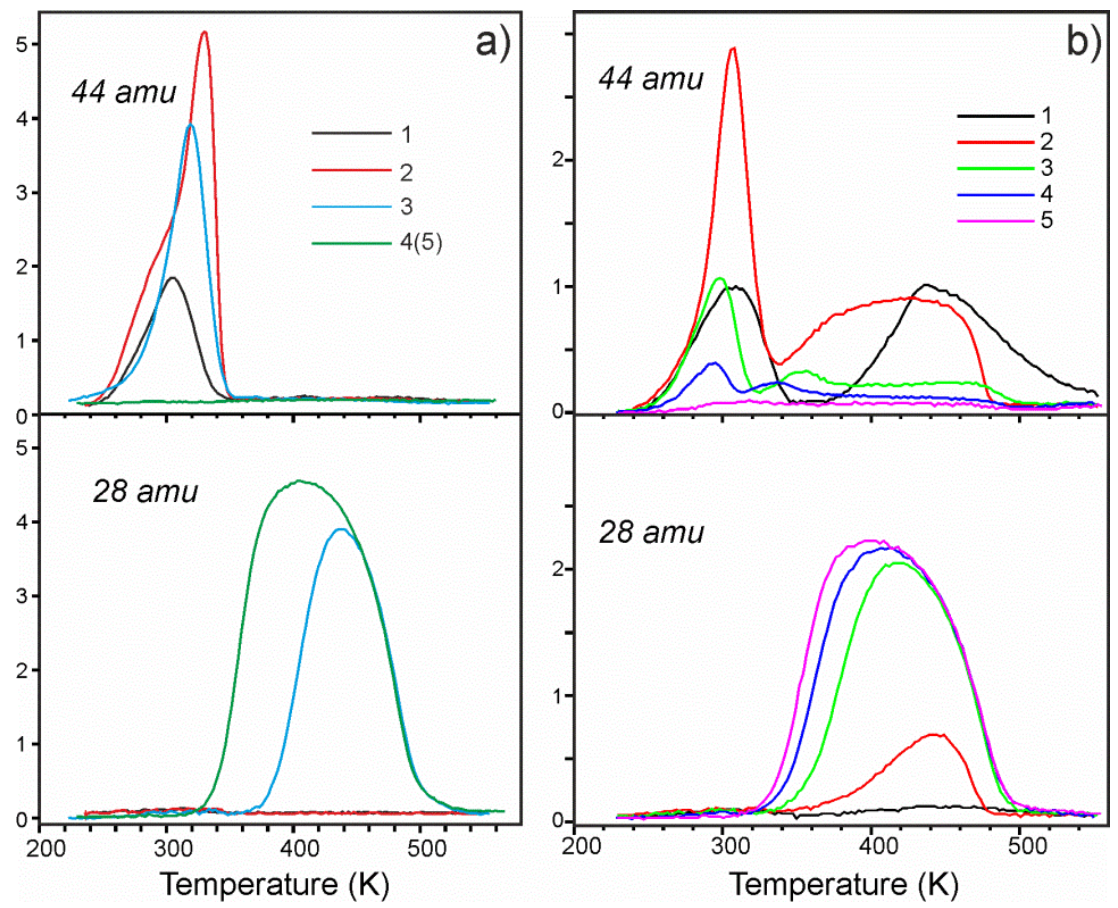

Figure 3. TPD spectra, showing $\mathrm{CO}_{2}(44 \mathrm{amu})$ and $\mathrm{CO}(28 \mathrm{amu})$ signals, from the $\mathrm{Pt}(111)$ (a) and the $0.6 \mathrm{ML}$ $\mathrm{FeO} / \mathrm{Pt}(111)$ (b) samples, both pre-treated in $20 \mathrm{mbar}$ of $\mathrm{O}_{2}$ at $450 \mathrm{~K}$ for $10 \mathrm{~min}$. The spectra were repeatedly measured $n$ times, as indicated, and each time $1 \mathrm{~L} \mathrm{CO}$ was adsorbed at $\sim 220 \mathrm{~K}$. The heating rate is $3 \mathrm{~K} / \mathrm{s}$.

We first address the TPD results for bare Pt(111) (Fig. 3a). The first CO exposure only resulted in the $\mathrm{CO}_{2}$ signal (at $\sim 305 \mathrm{~K}$ ) indicating that all adsorbed $\mathrm{CO}$ molecules reacted with oxygen to form $\mathrm{CO}_{2}$. The $\mathrm{CO}_{2}$ production was the highest in the second TPD run. Obviously, the reduced $\mathrm{O}$ coverage due to the reaction with $\mathrm{CO}$ in the previous run allows more $\mathrm{CO}$ to adsorb and react. In the next runs, the $\mathrm{CO}_{2}$ formation attenuates due to the lack of $\mathrm{O}$ atoms, and the CO signal converged to the one obtained on the clean Pt(111) surface. Oxygen consumption by the reaction with $\mathrm{CO}$ was monitored by recording 32 amu $\left(\mathrm{O}_{2}\right)$ signal (see Figure S1a in Supporting Information), which on the bare surface exhibited a broad signal peaked at $~ 650 \mathrm{~K}$ and a prominent shoulder at $\sim 560 \mathrm{~K}$. The latter is associated either with ultrathin $\mathrm{PtO}_{\mathrm{x}}$ overlayer or sub-surface oxygen species, both formed only at high $\mathrm{O}_{2}$ chemical potentials. ${ }^{[16]}$ Regardless of its precise origin, this oxygen is found to be consumed first. However, the total amounts of $\mathrm{CO}_{2}$ produced in repeated $\mathrm{CO}$ TPD spectra linearly correlates with the $\mathrm{O}_{2}$ uptake (Figure S1b), i.e. independently on the nature of oxygen species. It, therefore, appears that the reaction first occurs between adsorbed $\mathrm{CO}$ and those surface $\mathrm{O}$ adatoms, which are more 
weakly bound because of its proximity to "oxidic" and/or sub-surface oxygen species. The latter continuously replenishes the $O$ atoms on the surface which then react with $\mathrm{CO}$ in further TPD runs.

Before we address $\mathrm{CO}$ oxidation on the $\mathrm{FeO}(111)$ covered $\mathrm{Pt}(111)$ surface, we note that $\mathrm{CO}$ adsorption on the "as grown" $\mathrm{FeO}(111)$ films did not result in any $\mathrm{CO}_{2}$ production at any oxide coverage. If only the sub-ML films, following the film preparation at $1000 \mathrm{~K}$ (see Experimental), were cooled down to $300 \mathrm{~K}$ in $10^{-6}$ mbar $\mathrm{O}_{2}$ ambient, then $\mathrm{CO}_{2}$ desorbing at $300 \mathrm{~K}$ was observed in TPD spectra. However, the amounts of $\mathrm{CO}_{2}$ reversely scaled with the $\mathrm{FeO}$ coverage (not shown), indicating that $\mathrm{CO}$ oxidation on the $\mathrm{FeO}(111) / \mathrm{Pt}(111)$ surfaces only occurs on the oxide uncovered $\mathrm{Pt}(111)$ areas.

For comparison, Figure 3b shows TPD results for an $0.6 \mathrm{ML} \mathrm{FeO(111)/Pt(111)} \mathrm{film} \mathrm{first}$ treated with $\mathrm{O}_{2}$ at high pressures at the same conditions as used for bare $\mathrm{Pt}(111)$ presented in Fig. 3a. Note that TPD spectra from a closed, i.e. $1 \mathrm{ML}$, film did not detect any desorption signals, implying that $\mathrm{CO}$ does not adsorb on the $\mathrm{FeO}_{2}$ terraces at these pressures (typically $10^{-6}$ mbar). On the sub-ML samples, no CO desorption other than obtained on $\mathrm{Pt}(111)$ is observed, thus suggesting that edges of the $\mathrm{FeO}_{2}$ islands do not provide additional adsorption sites to $\mathrm{CO}$. In fact, after several CO adsorption/desorption cycles, the CO signal converged to the one observed on the same film prior to the high pressure $\mathrm{O}_{2}$ treatment (see last two spectra in Fig. $3 \mathrm{~b}$ ). In contrast to $\mathrm{CO}, \mathrm{CO}_{2}$ is produced in two well separated temperature regimes. The first one at low temperatures (LT), i.e. around $300 \mathrm{~K}$, is virtually identical to that obtained for $\mathrm{Pt}$ (111) (Fig. 3a), and as such it is straightforwardly assigned to the reaction on open areas of $\mathrm{Pt}(111) . \mathrm{CO}_{2}$ production at high temperatures (HT), i.e. between 340 and $520 \mathrm{~K}$, obviously missing on the bare $\mathrm{Pt}(111)$ surface, must be assigned to reactions on $\mathrm{FeO}_{2} / \mathrm{Pt}(111)$ interface, as the closed film does not produce $\mathrm{CO}_{2}$ at these conditions. The $\mathrm{HT}$ signal is the most intense in the first two TPD runs. Then it attenuates substantially, although one may recognize features at $\sim 360 \mathrm{~K}$ in the $3-\mathrm{d}$ and $\sim 340 \mathrm{~K}$ in the 4-th runs. Interestingly, annealing to $1000 \mathrm{~K}$ during the 5-th run did not reveal $\mathrm{O}_{2}$ desorption at $\sim 800 \mathrm{~K}$ which was initially present in the sample before $\mathrm{CO}$ adsorption (see Fig. 2) and which is characteristic for the $\mathrm{FeO}_{2}$ trilayer structure. Therefore, all 
weakly bonded oxygen species associated with the $\mathrm{FeO}_{2}$ phase were ultimately consumed by the reaction with $\mathrm{CO}$ in these experiments.

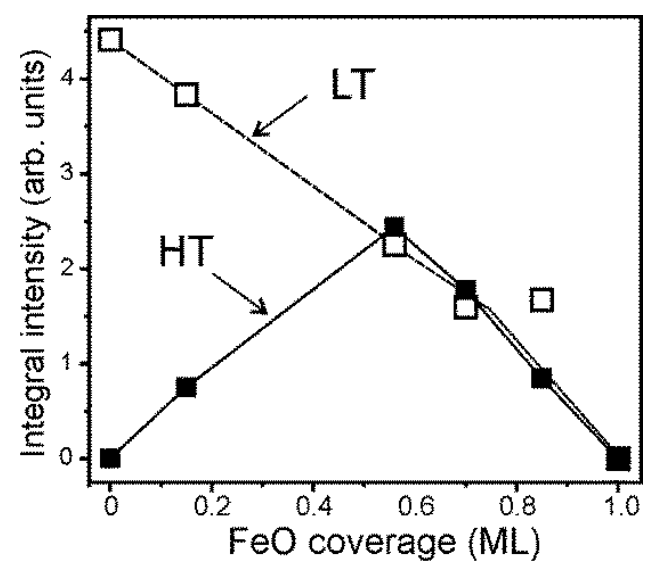

Figure 4. Total $\mathrm{CO}_{2}$ production measured in LT and $\mathrm{HT}$ regions in five consecutive CO TPD runs (see Fig. 3 for the $0.6 \mathrm{ML}$ sample) as a function of $\mathrm{FeO}$ coverage.

The same experiments were then conducted for various oxide coverages. Figure 4 depicts the total amounts of $\mathrm{CO}_{2}$ measured in five consecutive CO TPD spectra in the LT and HT regions, respectively, as a function of $\mathrm{FeO}(111)$ coverage in "as grown" films. It is clear that the LT signal, in essence, reversely scales with the oxide coverage and as such it is assigned to reaction on uncovered areas of $\mathrm{Pt}(111)$. The observed linear relationship suggests no oxygen spillover from $\mathrm{FeO}_{2}$ islands onto the $\mathrm{Pt}(111)$ surface. In contrast, $\mathrm{CO}_{2}$ production in the $\mathrm{HT}$ state goes through the maximum in the same manner as observed for the CO oxidation rate at near atmospheric pressures (Fig. 1b), both suggesting the reaction to occur on the interface between $\mathrm{Pt}(111)$ and $\mathrm{FeO}_{2}$ trilayer.

In addition, we measured the amount of weakly bonded oxygen remained after $\mathrm{CO}$ adsorption experiments. The results also revealed the coverage effect: While all samples at FeO coverages below $0.6 \mathrm{ML}$ showed no more weakly bonded oxygen in the $32 \mathrm{amu}\left(\mathrm{O}_{2}\right)$ signal after the 5-th CO TPD, the $0.85 \mathrm{ML}$ sample showed that only about $20 \%$ was consumed by the reaction with $\mathrm{CO}$. To recall, the closed film did not manifest reaction with $\mathrm{CO}$ under these conditions. All these findings indicate that oxygen reacting at the interface may be repopulated 
by oxygen from the interior parts of the $\mathrm{FeO}_{2}$ islands during heating to $550 \mathrm{~K}$ and/or cooling down for the next $\mathrm{CO}$ adsorption. This may also explain the relatively broad HT signal and also some featuring (see, for example, peaks at $350 \mathrm{~K}$ for the $0.6 \mathrm{ML}$ sample, see Fig. 3b) which may be caused by the simultaneous oxygen migration to the oxide rim on heating. Certainly, at high oxide coverages and large island sizes, oxygen consumption by $\mathrm{CO}$ reacting at oxide/metal interface is less pronounced than in the case of small islands.

Therefore, the combined experimental results provide compelling evidence that the enhanced reactivity observed for $\mathrm{FeO}$ partly covering the $\mathrm{Pt}(111)$ surface at realistic conditions is due to the reaction occurring at the rim of the $\mathrm{FeO}_{2}$ islands formed at high oxygen pressures. Indeed, any reactions on the top of $\mathrm{FeO}_{2}$ islands would be proportional to the oxide coverage, which is not the case. Whether the islands edges provide the most weakly bound oxygen and therefore become more readily reacting with an incoming $\mathrm{CO}$ molecule could not be judged solely by TPD. However, it seems more plausible that the oxide/metal interface is the most active simply because the $\mathrm{CO}$ molecules, involved in the reaction, adsorb on Pt sites in the proximity to the oxide. To end the catalytic cycle after $\mathrm{CO}_{2}$ desorption, oxygen must be replenished. Bao and co-workers considering only the $\mathrm{FeO}$ bilayer model have previously suggested $^{[9 b]}$ the replenishment to occur through $\mathrm{O}_{2}$ dissociation at the coordinatively unsaturated Fe-sites at the oxide edges. Although the FeO bilayer is certainly not the adequate one for reactions under realistic pressure conditions, we cannot exclude this scenario for the trilayer structure. However, our TPD results revealed that oxygen diffusion from the island interior to the edge sites may be operative as well.

\section{Theoretical Calculations}

To shed more light on reactivity of the FeO/Pt surfaces, we have performed DFT calculations to estimate the thermodynamic stability of oxygen at a variety of alternative terrace and boundary sites, characteristic of Pt-supported $\mathrm{FeO}_{x}$ film in sub-ML coverage. The computational model depicted in Fig. 5 represents an oxide coverage of $0.6 \mathrm{ML}$, with an equal proportion of $\mathrm{FeO}$ and $\mathrm{FeO}_{2}$, accounting for the case of large $\mathrm{FeO}_{x}$ islands on the $\mathrm{Pt}(111)$ surface. It consists of 
embedded $\mathrm{FeO}_{2}$ islands, with trilayer O-Fe-O structure, located primarily in the region of the socalled "hcp" lattice registry (O ions on-top of surface Pt atoms, Fe ions in the hollow sites), where the oxygen-rich film forms the most easily. ${ }^{[8 b]}$ Conversely, bare $\mathrm{FeO}(111)$ is most stable in regions of " $\mathrm{fcc}$ " registry (both $\mathrm{O}$ and Fe ions in three-fold hollow sites of a Pt(111) substrate). The large unit cell contains also the region of a bare $\mathrm{Pt}(111)$ surface created by removing the oxide from regions of "top" registry ( $\mathrm{O}$ ions in the hollow sites, Fe ions on-top of a surface $\mathrm{Pt}$ ), where the stability of a $\mathrm{FeO}_{\mathrm{x}}$ film is the lowest. ${ }^{[8 \mathrm{~b}, 17]}$

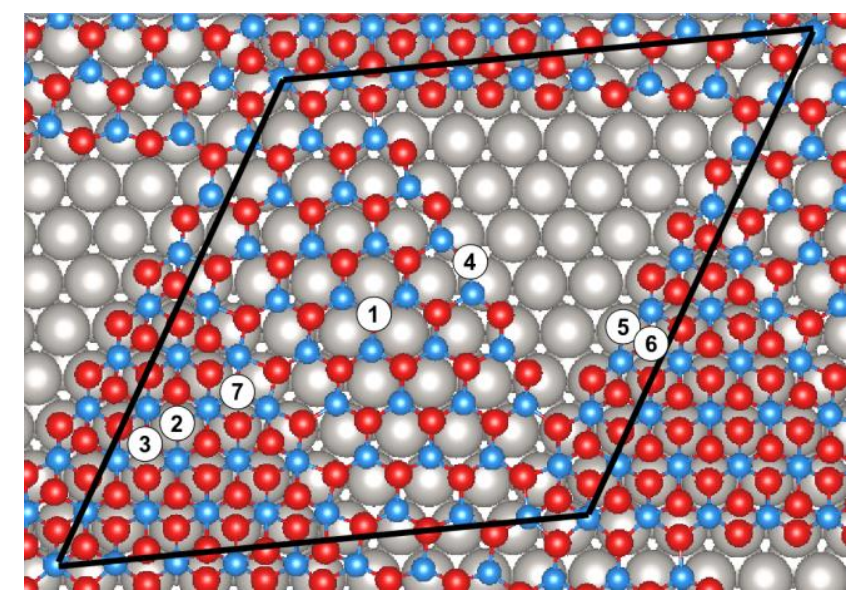

Figure 5. Computational model of a sub-monolayer $\mathrm{FeO}_{\mathrm{x}}$ film on the $\mathrm{Pt}(111)$ surface. The nonequivalent oxygen sites are labeled 1-7: $\mathrm{T}-\mathrm{FeO}(1), \mathrm{T}_{1}-\mathrm{FeO}_{2}(2), \mathrm{T}_{\mathrm{S}}-\mathrm{FeO}_{2}(3), \mathrm{E}-\mathrm{FeO} / \mathrm{Pt}(4), \mathrm{E}_{1}-\mathrm{FeO}_{2} / \mathrm{Pt}(5), \mathrm{E}_{\mathrm{S}}-\mathrm{FeO}_{2} / \mathrm{Pt}(6), \mathrm{E}-\mathrm{FeO} 2 / \mathrm{FeO}$ (7). $\mathrm{Pt}, \mathrm{O}$ and $\mathrm{Fe}$ atoms are represented by gray, red and blue spheres, respectively.

In the following we focus on three different types of boundary sites, labeled $E$ (edge): the oxide/oxide boundary $\left(\mathrm{E}-\mathrm{FeO}_{2} / \mathrm{FeO}\right)$ at the edge of the embedded $\mathrm{FeO}_{2}$ islands, and oxide/metal boundaries at either $\mathrm{FeO} / \mathrm{Pt}(\mathrm{E}-\mathrm{FeO} / \mathrm{Pt})$ or $\mathrm{FeO}_{2} / \mathrm{Pt}\left(\mathrm{E}-\mathrm{FeO}_{2} / \mathrm{Pt}\right)$ edge sites. Oxygen sites at $\mathrm{FeO}$ and $\mathrm{FeO}_{2}$ terraces ( $\mathrm{T}-\mathrm{FeO}$ and $\mathrm{T}-\mathrm{FeO}_{2}$, respectively) and $\mathrm{O}$ adsorbed at $\mathrm{Pt}(111)$ will be used as a benchmark. In the case of $\mathrm{FeO}_{2}$, oxygens in contact with vacuum, labeled $\mathrm{S}$ (surface), or in contact with Pt, labeled I (interface), will be systematically differentiated. 
Table 1. Calculated stability of oxygen at various sites of oxide sub-monolayer $\mathrm{FeO}_{x} / \mathrm{Pt}$ as depicted in Fig. 5. Oxygen extraction (vacancy formation) energy $\Delta E=E\left(\mathrm{FeO}_{x}\right.$ with an $\mathrm{O}$ vacancy) $+1 / 2 \mathrm{E}\left(\mathrm{O}_{2}\right)-\mathrm{E}\left(\mathrm{FeO}_{\mathrm{x}}\right)$ and corresponding desorption temperatures $T_{\max }$ (see text for details).

\begin{tabular}{lcc}
\hline Site & $\Delta \mathrm{E}(\mathrm{eV})$ & $\mathrm{T}_{\max }$ \\
\hline $\mathrm{T}-\mathrm{FeO}$ & 2.93 & 1175 \\
$\mathrm{~T}_{1}-\mathrm{FeO}_{2}$ & 1.67 & 765 \\
$\mathrm{~T}_{\mathrm{S}}-\mathrm{FeO}_{2}$ & 2.15 & 920 \\
$\mathrm{E}-\mathrm{FeO} / \mathrm{Pt}$ & 2.13 & 915 \\
$\mathrm{E}_{1}-\mathrm{FeO}_{2} / \mathrm{Pt}$ & 1.58 & 735 \\
$\mathrm{E}_{\mathrm{S}}-\mathrm{FeO}_{2} / \mathrm{Pt}$ & 1.53 & 720 \\
$\mathrm{E}-\mathrm{FeO}_{2} / \mathrm{FeO}$ & 1.31 & 645 \\
\hline
\end{tabular}

The calculated oxygen stability characteristics at the eight considered sites are summarized in Table 1 . The vacancy formation energy $\Delta E$ shows a strong site-dependence and ranges from nearly $3 \mathrm{eV}$ for $\mathrm{FeO}$ terrace down to $1.3 \mathrm{eV}$ for $\mathrm{FeO}_{2} / \mathrm{FeO}$ boundary. We note that in this latter case $\Delta E$ is close to the calculated oxygen adsorption/desorption energy at the bare $\mathrm{Pt}(111)$ surface, which we find equal to $1.32 \mathrm{eV}$ (obtained with one $\mathrm{O}$ in a (2x2) surface cell). While for each of the two oxide phases oxygen at boundary sites $(E)$ is always less stable than at terraces $(\mathrm{T})$, i.e. consistent with the lower coordination of edge ions, oxygen extraction from $\mathrm{FeO}_{2}$ requires less energy as compared to $\mathrm{FeO}$. This is directly linked to the specificity of the $\mathrm{FeO}_{2} / \mathrm{Pt}$ nano-oxide, stabilized by a substantial electron transfer from the $\mathrm{Pt}(111)$ substrate, which enables anions to be fully reduced (formally $\mathrm{O}^{2-}$ ) and cations to keep the $\mathrm{Fe}^{3+}$ oxidation state. ${ }^{[8,}$ 18] The lowest $\Delta E$ values are found at boundaries of embedded $\mathrm{FeO}_{2}$ islands, either the oxide/metal $\left(\mathrm{FeO}_{2} / \mathrm{Pt}\right)$ or the oxide/oxide $\left(\mathrm{FeO}_{2} / \mathrm{FeO}\right)$ ones. Since upon oxygen extraction the electrons are back-transferred from $\mathrm{FeO}_{2}$ to the Pt substrate and the tri-layer tends to (locally) recover the quasi-planar FeO-like structure, such recovery is, indeed, more easy at boundaries of the $\mathrm{FeO}_{2}$ islands, where there are little or no structural constraints from neighboring atoms. $^{[14]}$ 
Comparison with our previous results ${ }^{[8 a, 14]}$ for the case of high oxide coverage reveals the sensitivity of oxygen extraction characteristics to the oxide coverage and to the local structure of the $\mathrm{FeO}_{x} / \mathrm{Pt}$ interface. As expected, compared to ref. ${ }^{[14]}, \Delta E$ at $\mathrm{T}-\mathrm{FeO}$ and $\mathrm{T}_{1}-\mathrm{FeO}_{2}$ are practically identical, showing a small effect of coverage for these terrace sites. Similarly, the present extraction energies at $\mathrm{E}-\mathrm{FeO} / \mathrm{Pt}$ and $\mathrm{E}-\mathrm{FeO}_{2} / \mathrm{FeO}$ sites differ by $5 \%$ only from those obtained for higher oxide coverage, the difference being due to a somewhat different position of the oxide edges with respect to the $\mathrm{Pt}(111)$ lattice. In contrast, results obtained for $\mathrm{T}_{\mathrm{S}}-\mathrm{FeO}_{2}$ and $\mathrm{E}-\mathrm{FeO}_{2} / \mathrm{Pt}$ sites are substantially different, with systematically larger oxygen extraction energies in the present $0.6 \mathrm{ML}$ case. We note that such strong sensitivity to oxide coverage concerns uniquely oxygen of the oxygen-rich $\mathrm{FeO}_{2-x}$ phase. Basically, the electron exchange with the metal substrate and the resulting charging of the Pt(111) surface required for stabilization of the $\mathrm{FeO}_{2}$ tri-layer makes the oxygen stability sensitive to the oxide coverage.

Calculated oxygen extraction energies can be linked to the experimental TPD data shown in Fig. 2 with the help of Redhead analysis, ${ }^{[19]}$ which links activation energy ( $E_{\text {des }}$ ) and the temperature for desorption maximum $\left(T_{\text {max }}\right): E_{\text {des }} / R T^{2}{ }_{\text {max }}=A / \beta \exp \left(-E_{\text {des }} / R T_{\text {max }}\right)$, where $R$ is the gas constant and $\beta$ is the heating rate. Table 1 presents the computed values of $T_{\max }$ for the various oxygen sites, obtained with rate $\beta=3 \mathrm{~K} / \mathrm{s}$ and the pre-exponential factor $A \sim 10^{13} \mathrm{~s}^{-1}$, commonly used for desorption of atoms and small molecules. We have assumed a linear relationship between desorption activation energy $E_{\text {des }}$ and extraction energies $\Delta E: E_{\text {des }}=a \Delta E+$ $\mathrm{b}, \mathrm{a}=0.93$ and $\mathrm{b}=0.55 \mathrm{eV}$, adjusted so to reproduce the experimental desorption temperatures from a complete $\mathrm{FeO}(111) / \mathrm{Pt}$ film $(1190 \mathrm{~K})$ and from a bare $\mathrm{Pt}(111)$ surface (650 K). The results prove that oxygen extracted from the embedded $\mathrm{FeO}_{2}$ islands alone can be responsible for the main features of the observed oxygen desorption spectra in Fig. 2. On the one hand, we find that desorption from $\mathrm{FeO}_{2}$ terraces $\left(\mathrm{T}-\mathrm{FeO}_{2}\right)$ occurs slightly below $800 \mathrm{~K}(\Delta E=$ $1.67 \mathrm{eV})$ i.e. at a lower temperature than obtained for a monolayer coverage $\left(\sim 850 \mathrm{~K}^{[8 \mathrm{a}]}\right)$, for which the calculated oxygen extraction energy $\Delta E$ is found to be $1.70 \mathrm{eV}^{[14]}$ On the other hand, desorption from $\mathrm{FeO}_{2} / \mathrm{Pt}$ boundaries may account for the feature observed at about $700 \mathrm{~K}$ as a shoulder to the main peak. We note also that the sensitivity of $\Delta E\left(\mathrm{FeO}_{2} / \mathrm{Pt}\right)$ to the oxide 
coverage discussed above is consistent with the relatively large width of the TPD feature. Finally, due to their close values for $\Delta E$, contribution from $\mathrm{FeO}_{2} / \mathrm{FeO}$ boundaries overlaps with the signal coming from oxygen on the bare Pt(111) surface.

While the oxygen extraction thermodynamics clearly identifies edge $\left(\mathrm{E}-\mathrm{FeO}_{2} / \mathrm{Pt}\right.$ and $\mathrm{E}-$ $\mathrm{FeO}_{2} / \mathrm{FeO}$ ) sites as the most plausible candidates for $\mathrm{CO}$ oxidation (with a small preference for the latter), we complement the picture by an analysis of $\mathrm{CO}$ adsorption characteristics at these two boundaries.

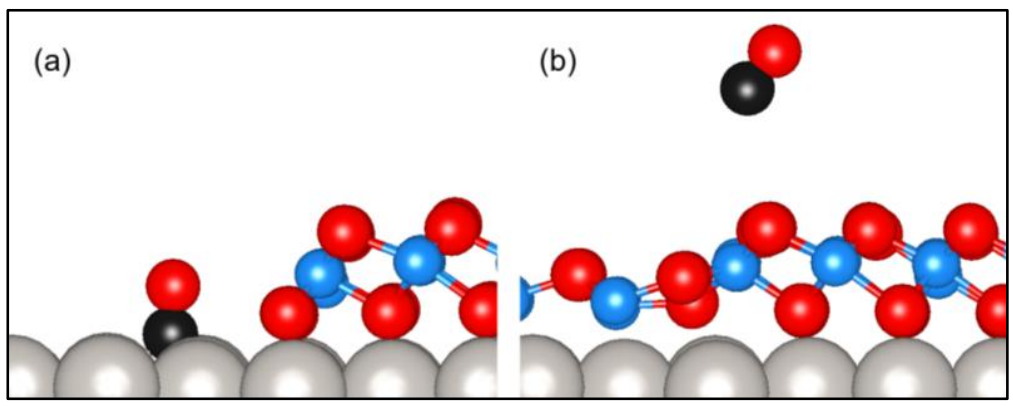

Figure 6. Most stable $\mathrm{CO}$ adsorption configurations at the $\mathrm{FeO}_{2} / \mathrm{Pt}(\mathrm{a})$ and $\mathrm{FeO}_{2} / \mathrm{FeO}$ (b) boundaries depicted in Fig. 5. Pt, O, C and Fe atoms are represented by gray, red, black, and blue spheres, respectively.

As far as the $\mathrm{FeO}_{2} / \mathrm{Pt}$ boundary is concerned (Fig 6a), our GGA calculations predict preferential CO adsorption at the neighboring hollow site of the $\mathrm{Pt}(111)$ surface, with a large adsorption energy $\mathrm{E}_{\mathrm{ads}}\left(\mathrm{FeO}_{2} / \mathrm{Pt}\right)=2.05 \mathrm{eV}$. These adsorption characteristics are clearly reminiscent of those of a $\mathrm{CO}$ molecule on a bare $\mathrm{Pt}(111)$ surface, for which our present simulation predicts a somewhat stronger adsorption $\mathrm{E}_{\mathrm{ads}}(\mathrm{Pt})=2.19 \mathrm{eV}$ (obtained with one CO molecule on a ( $2 \times 2)$ surface cell). As a consequence, thermodynamics of both $\mathrm{CO}$ and $\mathrm{O}$ at the $\mathrm{FeO}_{2} / \mathrm{Pt}$ boundary bears close similarity to their adsorption/desorption characteristics at the bare $\mathrm{Pt}(111)$ surface. However, the small reduction of CO-Pt bonding strength found in the direct vicinity of the $\mathrm{FeO}_{2} / \mathrm{Pt}$ edge is expected to reduce the barrier for the $\mathrm{CO}+\mathrm{O} \rightarrow \mathrm{CO}_{2}$ reaction. Not surprisingly, it also suggests a sensitivity of reaction thermodynamics and kinetics to the oxide coverage and precise metal-oxide registry, in line with the sensitivity of the oxygen extraction energies discussed above. 
Conversely, $\mathrm{CO}$ adsorption at the $\mathrm{FeO}_{2} / \mathrm{FeO}$ boundary (Fig. 6b) is very weak, with an adsorption energy $\mathrm{E}_{\mathrm{ads}}\left(\mathrm{FeO}_{2} / \mathrm{FeO}\right)=0.05 \mathrm{eV}$. This value is only little higher than those obtained for $\mathrm{FeO}$ and $\mathrm{FeO}_{2}$ terraces $(0.03 \mathrm{eV}$ and $0.01 \mathrm{eV}$, respectively, obtained for a single $\mathrm{CO}$ molecule on a (2x2) surface cell). It is noteworthy that, while van der Waals interactions (optB88-vdW ${ }^{[20]}$ ) increase the $\mathrm{CO}$ adsorption energy at terraces by about $0.1 \mathrm{eV}$, the effect is small, and it does not bring to a qualitative change to the stability of these weakly bound configurations. In any case, such small adsorption energies do not result in CO chemisorption to the oxide surface under the experimental conditions.

While the strength of oxygen bonding at the $\mathrm{FeO}_{2} / \mathrm{Pt}$ and $\mathrm{FeO}_{2} / \mathrm{FeO}$ boundaries differs only little (1.5 eV vs $1.3 \mathrm{eV}$ ), the very different characteristics of $\mathrm{CO}$ adsorption (2.05 eV vs 0.05 eV) clearly indicates that these two sites have a different efficiency for CO oxidation. Indeed, since $\mathrm{CO}$ binds only weakly to the $\mathrm{FeO}_{2} / \mathrm{FeO}$ boundary, the Eley-Rideal reaction mechanism is anticipated on these sites. Conversely, strong $\mathrm{CO}$ binding in the direct vicinity of the $\mathrm{FeO}_{2} / \mathrm{Pt}$ boundaries makes the Langmuir-Hinshelwood mechanism operative. Although in the latter case $\mathrm{CO}$ and $\mathrm{O}$ binding characteristics are close to those obtained on the bare $\mathrm{Pt}(111)$ surface, the $\mathrm{FeO}_{2}$ oxide phase provides $\mathrm{O}$ atoms which do not suffer from the $\mathrm{CO}$ blocking effect which, otherwise, poisons the $\mathrm{CO}$ oxidation reaction on the bare Pt surface.

\section{CONCLUSIONS}

The experimental results showed much higher reactivity of $\mathrm{FeO}(111)$ films partly covering the $\mathrm{Pt}(111)$ surface than the closed films. Temperature programmed desorption results showed that the "as grown" $\mathrm{FeO}(111)$ bilayer islands are, in fact, inert towards $\mathrm{CO}_{2}$ formation. Only the $\mathrm{FeO}_{2-x}$ trilayer structures, which are formed at high oxygen pressures, showed substantial $\mathrm{CO}_{2}$ production that reaches a maximum at $\sim 40 \%$ coverage, i.e. nearly the same as observed for the CO oxidation rate measured at near-atmospheric pressures. Corroborated by DFT calculations, the rate enhancement at sub-monolayer oxide coverages is assigned to the reaction at the oxide/metal boundary, between $\mathrm{CO}$ adsorbed on $\mathrm{Pt}(111)$ and oxygen at the edge sites of the $\mathrm{FeO}_{2}$ trilayer islands. DFT-computed oxygen extraction 
characteristics clearly identify the boundaries of the $\mathrm{FeO}_{2}$ phase as the preferential source of weakly bound oxygen. Although oxygen atoms are bound even more weakly at the $\mathrm{FeO}_{2} / \mathrm{FeO}$ boundaries as compared to the $\mathrm{FeO}_{2} / \mathrm{Pt}$ one, the reaction pathway is determined by their $\mathrm{CO}$ adsorption characteristics which differ substantially. $\mathrm{CO}$ adsorbs very weakly at $\mathrm{FeO}_{2} / \mathrm{FeO}$ boundaries, thus leading to a less efficient Eley-Rideal type mechanism. Conversely, CO adsorption on $\mathrm{Pt}(111)$ in the vicinity to the $\mathrm{FeO}_{2}$ island edges is as strong as on $\mathrm{Pt}(111)$, thus favoring a more efficient Langmuir-Hinshelwood mechanism. However, contrary to bare $\mathrm{Pt}(111)$, reaction at the $\mathrm{FeO}_{2} / \mathrm{Pt}$ boundary is not affected by $\mathrm{CO}$ blocking the oxygen dissociation. In the course of catalytic reaction, the $\mathrm{FeO}_{2}$ islands provide a reservoir of weakly bonded oxygen, which is continuously repopulated by oxygen dissociation and subsequent migration across the $\mathrm{FeO}_{2-x}$ islands to the active edge sites. As to better quantify the efficiency of the two reaction types, the calculations of the reaction pathway and associated activation barriers and their dependence on the oxide coverage and metal-oxide registry are currently in progress.

Certainly, for the rate enhancement to occur CO must adsorb sufficiently strongly, otherwise it desorbs intact before reaction with oxygen. Therefore, weakly adsorbing metal surfaces, such as $\mathrm{Ag}(111)$, do not show such effect as previously reported for $\mathrm{ZnO}(0001)$ films. ${ }^{[4]}$ Accordingly, using oxygen bonding energy as a principal descriptor for CO oxidation over ultrathin oxide films seems to be valid only for the systems exhibiting relatively weak CO adsorption which does not compete for oxygen adsorption sites. In the case of systems exposing a metal/oxide interface, the reactivity may be considerably enhanced by metals

strongly adsorbing CO like Pt. In such cases, the model of overlapping states ${ }^{[21]}$ seems to be fairly predictive, suggesting high activity when the desorption profiles for each individual molecule reacting at the surface overlap.

\section{Experimental Methods}

The experiments were performed in an UHV chamber (base pressure below $2 \times 10^{-10} \mathrm{mbar}$ ) equipped with low energy electron diffraction (LEED), Auger electron spectroscopy (AES), and 
quadrupole mass-spectrometer (QMS, from Hiden) for TPD measurements. The Pt(111) single crystal was spot-welded to thin Ta wires for resistive heating. The crystal was cleaned using repeated cycles of $\mathrm{Ar}^{+}$bombardment and annealing in UHV at $\sim 1200 \mathrm{~K}$. Residual carbon was removed by oxidation at $\sim 900 \mathrm{~K}$ in $10^{-6}$ mbar of $\mathrm{O}_{2}$. Cleanliness of the crystal was checked by LEED, AES and CO TPD prior to each preparation of the $\mathrm{FeO}(111)$ films. The films were grown on $\mathrm{Pt}(111)$ kept at $300 \mathrm{~K}$ by Fe vapor deposition from a Fe rod (99.99\%, from Goodfellow) using commercial e-beam assisted evaporator (Focus EMT3), followed by annealing in $10^{-6} \mathrm{mbar}_{2}$ of $\mathrm{O}_{2}$ at $1000 \mathrm{~K}$ for $2 \mathrm{~min}$. The chamber houses a high-pressure reaction cell for reactivity studies at atmospheric pressures using a gas chromatograph (from Agilent) for the gas composition analysis. The reaction mixture (10 mbar $\mathrm{CO}$ and 50 mbar $\mathrm{O}_{2}$, balanced by He to 1 bar) was dosed at room temperature and circulated with a membrane pump for 20 min to reach constant flow. Then the sample was heated to the reaction temperature $450 \mathrm{~K}$ with a rate $1 \mathrm{~K} / \mathrm{s}$. After reaction the sample was cooled down to room temperature while the cell was pumped out down to $\sim 10^{-6} \mathrm{mbar}$ before it was evacuated for surface characterization.

\section{Computational Methods}

All DFT calculations were performed with the Vienna Ab-initio Simulation Package (VASP), ${ }^{\text {[22] }}$ using Projector Augmented Wave (PAW) method ${ }^{[23]}$ to represent the electron-core interaction, and the Perdew-Wang 91 (PW91) ${ }^{[24]}$ gradient-corrected exchange-correlation functional. Following our previous studies, ${ }^{[17]}$ iron oxides were treated with the DFT+U approach in the form proposed by Dudarev, ${ }^{[24]}$ with $\mathrm{U}_{\mathrm{Fe}}-\mathrm{J}_{\mathrm{Fe}}=3 \mathrm{eV}$. FeO $/ \mathrm{Pt}(111)$ system was represented by a three-layer-thick $\mathrm{Pt}(111)$ slab with the $\mathrm{FeO}_{x}$ oxide adsorbed on one side only. The two bottom Pt layers were hold fixed while the surface Pt layer and the oxide film were fully relaxed (threshold on forces equal to $0.01 \mathrm{eV} / \AA ̊$ ). The slabs were separated by at least $10 \AA ̊$ of vacuum and the so-called dipole corrections were applied in order to eliminate the residual dipoles in the direction perpendicular to the surface. In order to take into account the effect of lattice mismatch between the $\mathrm{Pt}(111)$ substrate and the $\mathrm{FeO}_{\mathrm{x}}$ oxide layer and to mimic the coincidence 
structures observed experimentally, ${ }^{[25]}$ a $(\sqrt{ } 73 \times \sqrt{ } 73) \mathrm{R} 5.8^{\circ}-\mathrm{FeO}(111) / /(\sqrt{ } 91 \times \sqrt{ } 91) \mathrm{R} 5.2^{\circ}-\mathrm{Pt}(111)$

periodic supercell has been used. It contains 415 atoms per unit cell, making $\Gamma$ point sufficient to sample the Brillouin zone. In all calculations, we have used soft oxygen and carbon pseudopotentials (energy cutoff of $280 \mathrm{eV})^{[26]}$ and imposed a row-wise anti-ferromagnetic alignment of Fe spins. ${ }^{[17]}$

\section{Acknowledgments}

The authors from FHI acknowledge Cluster of Excellence UNICAT administered by TU Berlin, and SFB 1109 administered by HU Berlin, and Fonds der Chemischen Industrie for financial support. X.W. thanks China Scholarship Council for the fellowship. The work of LG and GP was supported by the FIRB Project RBAP115AYN “Oxides at the nanoscale: multifunctionality and applications". The authors acknowledge the COST Action CM1104.

\section{References}

[1] S. Shaikhutdinov, H.-J. Freund, Annual Review of Physical Chemistry 2012, 63, 619-633.

[2] Y. Martynova, S. Shaikhutdinov, H.-J. Freund, Chemcatchem 2013, 5, 2162-2166.

[3] Y. Martynova, B. H. Liu, M. E. McBriarty, I. M. N. Groot, M. J. Bedzyk, S. Shaikhutdinov, H. J. Freund, Journal of Catalysis 2013, 301, 227-232.

[4] Q. Pan, B. H. Liu, M. E. McBriarty, Y. Martynova, I. M. N. Groot, S. Wang, M. J. Bedzyk, S. Shaikhutdinov, H. J. Freund, Catalysis Letters 2014, 144, 648-655.

[5] S. J. Tauster, Accounts of Chemical Research 1987, 20, 389-394.

[6] aM. Lewandowski, Y. N. Sun, Z. H. Qin, S. Shaikhutdinov, H. J. Freund, Applied Catalysis aGeneral 2011, 391, 407-410; bM. G. Willinger, W. Zhang, O. Bondarchuk, S. Shaikhutdinov, H.-J. Freund, R. Schlögl, Angewandte Chemie International Edition 2014, 53, 5998-6001.

[7] G. H. Vurens, M. Salmeron, G. A. Somorjai, Surface Science 1988, 201, 129-144.

[8] aY.-N. Sun, L. Giordano, J. Goniakowski, M. Lewandowski, Z.-H. Qin, C. Noguera, S. Shaikhutdinov, G. Pacchioni, H.-J. Freund, Angewandte Chemie-International Edition 2010, 49, 4418-4421; bL. Giordano, M. Lewandowski, I. M. N. Groot, Y. N. Sun, J. Goniakowski, C. Noguera, S. Shaikhutdinov, G. Pacchioni, H. J. Freund, Journal of Physical Chemistry C 2010, 114, 2150421509.

[9] aQ. Fu, F. Yang, X. Bao, Accounts of Chemical Research 2013, 46, 1692-1701; bD. Sun, X.-K. Gu, R. Ouyang, H.-Y. Su, Q. Fu, X. Bao, W.-X. Li, The Journal of Physical Chemistry C 2012, 116, 74917498; cQ. Fu, W.-X. Li, Y. Yao, H. Liu, H.-Y. Su, D. Ma, X.-K. Gu, L. Chen, Z. Wang, H. Zhang, B. Wang, X. Bao, Science 2010, 328, 1141-1144.

[10] H. Zeuthen, W. Kudernatsch, L. R. Merte, L. K. Ono, L. Lammich, F. Besenbacher, S. Wendt, ACS Nano 2015, 9, 573-583. 
[11] Q. Fu, Y. Yao, X. Guo, M. Wei, Y. Ning, H. Liu, F. Yang, Z. Liu, X. Bao, Physical Chemistry Chemical Physics 2013, 15, 14708-14714.

[12] Y. Yao, Q. Fu, Z. Wang, D. Tan, X. Bao, The Journal of Physical Chemistry C 2010, 114, 1706917079.

[13] L. Xu, Z. Wu, Y. Jin, Y. Ma, W. Huang, Physical Chemistry Chemical Physics 2013, 15, 1206812074.

[14] L. Giordano, G. Pacchioni, C. Noguera, J. Goniakowski, ChemCatChem 2014, 6, 185-190.

[15] Y. N. Sun, Z. H. Qin, M. Lewandowski, E. Carrasco, M. Sterrer, S. Shaikhutdinov, H. J. Freund, Journal of Catalysis 2009, 266, 359-368.

[16] aD. Bashlakov, L. F. Juurlink, M. M. Koper, A. Yanson, Catalysis Letters 2012, 142, 1-6; bH. Steininger, S. Lehwald, H. Ibach, Surface Science 1982, 123, 1-17; cJ. L. Gland, B. A. Sexton, G. B. Fisher, Surface Science 1980, 95, 587-602; dN. R. Avery, Chemical Physics Letters 1983, 96, 371373.

[17] L. Giordano, G. Pacchioni, J. Goniakowski, N. Nilius, E. D. L. Rienks, H.-J. Freund, Physical Review B 2007, 76, 075416.

[18] L. Giordano, G. Pacchioni, C. Noguera, J. Goniakowski, Topics in Catalysis 2013, 56, 1074-1081.

[19] P. A. Redhead, Vacuum 1962, 12, 203-211.

[20] aM. Dion, H. Rydberg, E. Schröder, D. C. Langreth, B. I. Lundqvist, Physical Review Letters 2004, 92, 246401; bJ. Klimeš, D. R. Bowler, A. Michaelides, Physical Review B 2011, 83, 195131; cK. Jiří, R. B. David, M. Angelos, Journal of Physics: Condensed Matter 2010, 22, 022201.

[21] A. M. Doyle, S. K. Shaikhutdinov, H. J. Freund, Journal of Catalysis 2004, 223, 444-453.

[22] G. Kresse, J. Furthmüller, Physical Review B 1996, 54, 11169-11186.

[23] G. Kresse, D. Joubert, Physical Review B 1999, 59, 1758-1775.

[24] J. P. Perdew, J. A. Chevary, S. H. Vosko, K. A. Jackson, M. R. Pederson, D. J. Singh, C. Fiolhais, Physical Review B 1992, 46, 6671-6687.

[25] M. Ritter, W. Ranke, W. Weiss, Physical Review B 1998, 57, 7240-7251.

[26] W. Zhang, Z. Li, Y. Luo, J. Yang, The Journal of Physical Chemistry C 2009, 113, 8302-8305. 
TOC graph

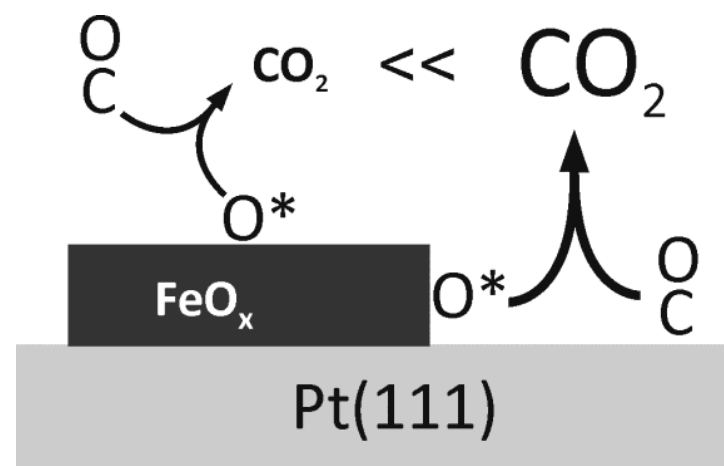

